\title{
Qualitative community stability determines parasite establishment and richness in estuarine marshes
}

The establishment of parasites with complex life cycles is generally thought to be regulated by free-living species richness and the stability of local ecological interactions. In this study, we test the prediction that stable host communities are prerequisite for the establishment of complex multi-host parasite life cycles. The colonization of naïve killifish, Fundulus heteroclitus, by parasites was investigated in 4 salt marsh sites that differed in time since major ecological restoration, and which provided a gradient in free-living species richness. The richness of the parasite community, and the rate at which parasite species accumulated in the killifish, were similar between the low diversity unrestored site and the two high diversity (10- and 20- year) restored marsh sites. The parasite community in the newly restored marsh (0 year) included only directly-transmitted parasite species. To explain the paradox of a low diversity, highly invaded salt marsh (unrestored) having the same parasite community as highly diverse restored marsh sites (10 and 20 yrs) we assessed qualitative community stability. We find a significant correlation between system stability and parasite species richness.

These data suggest a role for local stability in parasite community assembly, and support the idea that stable trophic relationships are required for the persistence of complex parasite life cycles. 


\section{Tavis K. Anderson* and Michael V.K. Sukhdeo}

2

3 Graduate Program in Ecology \& Evolution and Department of Ecology, Evolution \&

4 Natural Resources, Rutgers University, 14 College Farm Road, New Brunswick, NJ

5 08901, USA.

6

7

8

$9{ }^{*}$ Correspondence author and current address:

10 Tavis K. Anderson

11 Virus and Prion Research Unit

12 National Animal Disease Center, USDA-ARS

131920 Dayton Ave, PO Box 70

14 Ames, Iowa 50010, USA.

15 Ph: 515-337-6331; Fax: 515-337-7428

16 E-mail: tavis.anderson@ars.usda.gov 


\section{INTRODUCTION}

Parasites are considered to be ubiquitous components of ecosystems and the trophic strategy may represent more than $50 \%$ of potential interactions in food webs (Price 1980; de Meeûs \& Renaud 2002). This pervasive nature is reflected in their many roles in the regulation of competitive and predator/prey interactions (Hatcher, Dick, \& Dunn 2006), community structure (Dobson \& Hudson 1986; Wood et al. 2007), and ecosystem energy flow (Mouritsen \& Jensen 1994; Kuris et al. 2008). Additionally, there is a growing body of evidence which suggests that parasite species diversity is positively related to ecosystem functioning (Thomas, Guegan, \& Renaud 2005; Collinge \& Ray 2006). Indeed, recent theoretical work has suggested that stable communities may require a balance of antagonistic interactions (e.g., parasitism) with mutualistic interactions to achieve stability (Mougi \& Kondoh 2012). The underlying principle being that parasite life strategies are integrally coupled with populations of hosts, and that these hosts are critical not only for the parasites, but also to the dynamics of the free-living ecosystem (Poulin 2007).

The reliance of parasite species on free-living hosts for establishment and persistence is particularly true for those parasites with complex life cycles. Free-living hosts are essential habitats for the parasites, and also serve as a route of transmission via trophic interactions (Marcogliese \& Cone 1997; Marcogliese 2002). This co-dependence is reflected in host-parasite dynamics (Grenfell \& Dobson 1995; Poulin \& Thomas 1999), and has allowed the use of parasites as biological tags (Criscione, Cooper, \& Blouin 2006) and as metrics of ecosystem restoration success (Huspeni \& Lafferty 2004). Indeed, it is generally accepted that functioning ecosystems with robust structured 
organizations tend to be rich in parasites (Hudson, Dobson, \& Lafferty 2006; Dobson et al. 2008). It follows therefore, that the stability of free-living populations and the free-living community, should be reflected in the dynamics of the parasite community (reviewed in Lafferty et al. 2008). However, outside of a handful of studies using topological analyses to investigate parasite diversity (e.g., Chen et al. 2008; Anderson \& Sukhdeo 2011), very few studies have considered the impact of free-living community dynamics upon the parasite community. Thus, there is scant empirical evidence to support the notion that the stability of the free-living community is a requirement in parasite establishment, or for the persistence of parasite communities. Parasites have high host fidelity, and there should be a correlation between the success of establishment in a specific host population and the local stability of that community. Logically, a community that is locally stable (May 1972; 1973b; Ives \& Carpenter 2007; Allesina \& Tang 2012) represents a predictable resource for complex life cycle parasites to establish in or upon. The standard approach to quantifying local stability has been to generate community matrices, and determine the real part of the largest eigenvalue; if this value is negative the system is considered stable (May 1972). The generation of a community matrix, however, is challenging (i.e., it is difficult to measure interaction strengths to parameterize the community matrix), and alternate strategies have been developed that are based on the pattern of signs rather than their magnitude (May 1972; 1973b; Allesina \& Pascual 2008). This approach is particularly tractable given the preponderance of topology-based food webs; the food web adjacency matrix is assigned random interaction coefficients (i.e., transformed to a community matrix), the dominant eigenvalue is calculated, and the process iterated (Allesina \& 
63 Pascual 2008). In doing so, qualitative comparisons of local stability are possible (May

64 1973b; Allesina \& Pascual 2008). Specifically, a community that is more qualitatively

65 stable, is stable proportionally more often than systems that are not.

66 To assess the relationship between community stability and parasite

67 establishment, we conducted a natural field experiment documenting parasite

68 colonization of a naïve focal fish species within four salt marshes of differing local

69 stabilities. We asked the question, does qualitative stability have an impact on the

70 establishment of complex parasite life cycles? We report that complex life cycle parasites

71 are present in all but the least stable food web, and propose that stability in the free-living

72 trophic network constrains the establishment and persistence of complex life cycle

73 parasites.

(a) Defining the study system

We conducted our study of parasite establishment within an area where over $90 \%$

78 of estuarine marshes are heavily impacted due to decades of anthropogenic disturbances.

79 Recent large-scale restoration projects with the goal to recreate 'pristine' New-England

80 type salt marshes, enhancing and creating a variety of marsh habitats for wildlife, have

81 created spatially delineated habitats reflecting a gradient in time since restoration: Mill

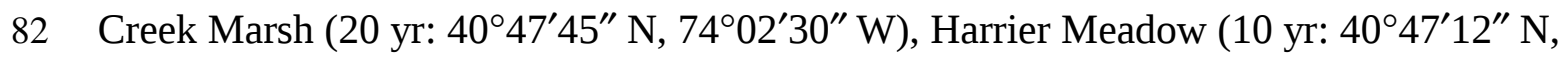

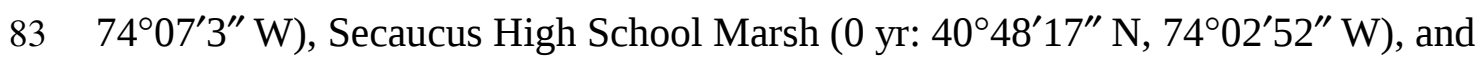

84 Oritani Marsh (unrestored: $40^{\circ} 47^{\prime} 57^{\prime \prime} \mathrm{N}, 74^{\circ} 05^{\prime} 07^{\prime \prime} \mathrm{W}$ ). Data on the free-living 
community and the construction of trophic food web networks has been previously described (Anderson 2009; Anderson \& Sukhdeo 2011).

\section{(b) Field collections}

We use the parasite community of a focal species, the common marsh killifish Fundulus heteroclitus, to assess the impact of community stability on parasite establishment. In our marshes, the host community (benthic invertebrates, birds, fishes) potentially transmit 11 species of helminth parasites to the common killifish (Anderson \& Sukhdeo 2010; 2011; in press). We collected approximately 2000 fish from Kingsland Impoundment, a marsh area abutting our Harrier Meadow site. Upon capture, killifish were held in plastic cattle watering tanks $(1.52 \mathrm{~m}$ in diameter and $0.61 \mathrm{~m}$ deep: containing 1000 L of water pumped from Kingsland Impoundment) for 7 days. The killifish were subjected to a series of anthelminthic treatments for 5 consecutive days, with the addition of metronidazole, praziquantel, levamisole and piperazine in standard concentrations (Bishop 2005). Following treatment, fish were held in recovery tanks for 2 days. Prior to stocking field cages at each site, 30 fish $(n=120$ total necropsied) were removed from the recovery tank and dissected to ensure the treatment process was effective and establish a time zero parasite community value. Three cages (2.4 m long, $2.4 \mathrm{~m}$ wide, and $1.5 \mathrm{~m}$ deep) were placed in each of the four marsh sites. Each cage was made of plastic-coated galvanized wire panels with $1 \mathrm{~cm}$ mesh, this allowed for water flow and benthic macroinvertebrate colonization but excluded predators. Cages were placed in marsh sites two weeks prior to stocking. Following our fish treatment and recovery regime, we stocked each cage with 150 
108 killifish. The resulting density $\left(17 \mathrm{fish} / \mathrm{m}^{3}\right)$ was within the natural variation exhibited by

109 local killifish populations. We placed the cages in water that ranged from $1.0 \mathrm{~m}-1.5 \mathrm{~m}$

110 in depth; there was no halocline in the range in which the cages were placed. To

111 eliminate the possibility that differences in cage placement or construction may affect the

112 results, cage location within each marsh was determined randomly. Fish cages were

113 sampled weekly for four weeks; at each sampling date 10 fish were removed from each

114 cage ( $\mathrm{n}=30$ per site each week). After the first 4 weeks, cages were sampled every two

115 weeks ( $\mathrm{n}=30$ per site) until cages were exhausted. Given prohibitive labor and time

116 restrictions, a subsample of 15 fish were necropsied immediately after collection at each

117 site. The fish were placed in a buffered $300 \mathrm{mg} / \mathrm{L}$ solution of tricaine methanesulfonate

118 (MS-222) until cessation of opercula movement, followed by pithing of the brain and

119 spinal cord. The MS-222 solution, and all external surfaces were examined for

120 ectoparasites using a stereomicroscope. The eyes and gills were removed and

121 individually examined with each gill arch examined separately. The viscera were

122 removed and internal body organs were examined using a stereomicroscope. All

123 helminths were heat fixed and stored in $70 \%$ ethanol pending examination.

124 Platyhelminths and acanthocephalans were stained with acetocarmine and mounted in

125 Permount. Nematodes were fixed and stored in a mixture of 5\% glycerol and $70 \%$

126 ethanol, and identified after approximately 2 wk. Helminth parasites collected during

127 necropsy were identified using the keys of Hoffman (1999), Anderson, Chabaud, \&

128 Willmott (1974), Schell (1970) and primary literature (Harris \& Vogelbein 2006).

129 Field collections were conducted under scientific permits issued by the New

130 Jersey Department of Environmental Protection, Division of Fish and Wildlife, Marine 
131 Fisheries Administration (\#0558, \#0628, \#0746) and Bureau of Freshwater Fisheries

132 (\#0536, \#06008, \#07019). Fish euthanasia was in accordance with the 2000 Report of the

133 American Veterinary Medical Association Panel on Euthanasia and approved by The

134 Animal Care and Facilities Committee at Rutgers University (\#00-012).

135

136

(c) Analysis of parasite community establishment

137

To document parasite species richness, we used species accumulation curves

138 (SACs) implemented using the bias-corrected Chao2 estimator in EstimateS 8.0.0

139 (Colwell 2006). Sample order was randomized 100 times without replacement and mean

140 species richness was estimated for each sample. We calculated the fit of the asymptotic

141 Michaelis-Menten equation $y=a x /(b+x)$, where $y$ is observed richness, $x$ is sample

142 size, $a$ is the asymptote or predicted richness and $b$ is a measure of the rate at which the

143 curve approaches the asymptote. A Kruskal-Wallis one-way analysis of variance

144 (ANOVA) was used on mean species richness to determine whether there were

145 significant differences between sites; multiple pairwise comparison was conducted using

146 Dunn's test.

147

148 (d) Community stability analyses

149 Food web stability was assessed using the framework provided by (May 1972;

150 1973a) and extended by (Allesina \& Pascual 2008). It is based on the concept of food

151 web matrices and the dynamics of species densities in the network. May (1973)

152 demonstrated that the community may be described via a matrix of interactions, and that

153 this matrix has a series of characteristic eigenvalues and that a system will be locally 
154 stable if the eigenvalues have negative real parts. Our approach for generating

155 community matrices, and describing their characteristic eigenvalues is described in the

156 supplementary information.

157 We also calculated the connectance of our food web matrices where connectance

$158\left(C=L_{o} / S^{2}\right)$ is the number of realized links $\left(L_{o}\right)$ divided by the number of possible links

$159\left(S^{2}\right)$. Measured in this way, $C$ is the average fraction of species in a community

160 consumed by the average species, i.e. when $C=0$ no species consume each other and

161 when $C=1$ all species consume all other species and themselves. In order to allow for

162 between network comparisons of connectance we normalized the data following the

163 method of (Gilbert 2009):

164

$$
C_{n o r m(S)}=\frac{C_{(S)}-C_{\min (S)}}{1-C_{\min (S)}}
$$

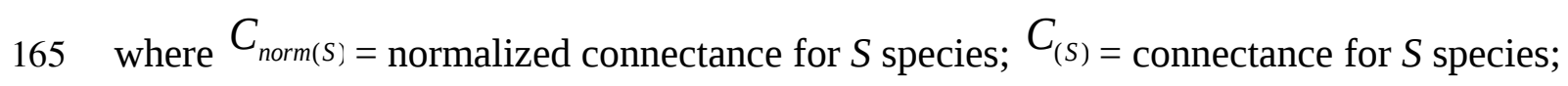

166 and $C_{\min (S)}=$ the minimum value of connectance for $S$ species.

\section{RESULTS}

A total of 600 fish were studied: 15 fish were necropsied from each of the collections (a subsample from the 30 fish collected) that occurred at each of the 4 sites over 10 samples, covering 14 weeks during the summer of 2008. Eight taxa of metazoan

172 parasites were identified including nematodes Dichelyne bullocki and Contracaecum sp.;

173 the digenean metacercaria of Ascocotyle diminuta and Posthodiplostomum minimum;

174 monogeneans Fundulotrema prolongis and Swingleus ancistrus; the acanthocephalan

175 Paratenuisentis ambiguous; the copepod Ergasilus funduli; these taxa infected more than 
$17670 \%$ of the killifish examined. Parasite intensity per host ranged from 1 to 2146 for the

177 directly transmitted monogeneans and copepod: parasite intensity per host ranged from 1

178 to 806 for the complex life cycle acanthocephalans, nematodes and digeneans.

179 The Oritani marsh (unrestored) included 71 species and had 5041 potential links

180 of which 629 were realized, resulting in a normalized connectance of 0.113 . The

181 Secaucus Marsh (0 year) included 87 species and had 7569 potential links of which 627

182 were realized, resulting in a normalized connectance of 0.072 . The restored marshes,

183 Harrier Marsh (10 year) and Mill Creek (20 year) included 112 and 122 species

184 respectively; the resulting values of normalized connectance were 0.088 for Harrier

185 Marsh and 0.117 for Mill Creek Marsh. The estimated parameters for each marsh are

186 summarized in Table 1.

187 Secaucus marsh (0 year) had a parasite community consisting only of the directly

188 transmitted monogenean S. ancistrus and the copepod E. funduli (Fig. 1). The remaining

189 three marsh sites recorded observations of all 8 species of metazoan parasites (direct and

190 complex life cycle) discovered during this study: Oritani Marsh (unrestored), Harrier

191 Marsh (10 year) and Mill Creek Marsh (20 year). The mean species richness and parasite

192 community displayed significant pairwise correlations between Oritani Marsh, Harrier

193 Marsh and Mill Creek Marsh (Table 2). The accumulation of parasite species in each

194 marsh was consistent with the asymptotic Michaelis-Menten equation: a steep slope with

195 an early asymptote (Fig. 1). The goodness-of-fit was adequate for: Oritani Marsh (Fig. 1:

$196 \mathrm{df}=149, r^{2}=0.53, \mathrm{SS}=58.64, \mathrm{~S}_{y x}=0.63$ ); Secaucus Marsh (Fig. 1: $\mathrm{df}=149, r^{2}=0.95$,

$197 \mathrm{SS}=0.51, \mathrm{~S}_{y x}=0.058$ ); Harrier Marsh (Fig. $1: \mathrm{df}=149, r^{2}=0.93, \mathrm{SS}=7.86, \mathrm{~S}_{y x}=0.23$ );

198 and Mill Creek Marsh (Fig. 1: $\mathrm{df}=149, r^{2}=0.76$, SS $=20.31, \mathrm{~S}_{y x}=0.37$ ). Overall mean 
199 species richness differed significantly between the four marsh sites (Fig. 1:

200 Kruskal-Wallis one-way ANOVA: $H=350.5, \mathrm{df}=3, p<0.0001$ ), with the mean species

201 richness at Secaucus marsh (0 year) significantly lower than the species richness

202 observed at the other three sites (Fig. 1: Dunn's multiple comparison test: $p<0.01$;

203 Secaucus mean $=1.1919 \pm 0.018 \mathrm{SE}$; Oritani mean $=7.447 \pm 0.055 \mathrm{SE}$; Harrier mean $=$

$2047.735 \pm 0.046$ SE; Mill Creek mean $=7.662 \pm 0.034$ SE). There was no significant

205 difference between the mean species richness observed at Oritani, Harrier and Mill Creek

206 marshes (Fig. 1: Dunn’s multiple comparison test: $p>0.05$ ).

207 For 100,000 randomizations of the community matrices generated from our four

208 food webs, Figure 2 shows the number of eigenvalues with a negative real part. None of

209 the food webs appear to satisfy the criteria of May (1973) for stability: given the random

210 interaction coefficients we imposed, no community matrix has $100 \%$ of the eigenvalues

211 with negative real parts. However, there were significant differences in the mean fraction

212 of eigenvalues with negative real parts between each of the marshes (One-way ANOVA

213 with Tukey's pairwise comparison: all $p<0.001)$. The Secaucus Marsh (0 year) exhibits

214 the lowest likelihood of achieving stability with a 77\% mean fraction of eigenvalues with

215 a negative real part (meanE), the maximum (maxE) and minimum (minE) fraction of

216 eigenvalues attained for this food web were $78 \%$ and $75 \%$ respectively (Table 1). Mill

217 Creek marsh, our oldest restoration (20 year) and highest diversity site, has a mean

218 fraction of eigenvalues with negative real parts of 80.3\%. Oritani Marsh (unrestored) has

219 a mean fraction of eigenvalues with negative real parts of 83.9\%. Harrier Marsh (10

220 year) has a mean fraction of eigenvalues with negative real parts of $85.1 \%$. These data

221 are aped by our normalized connectance values (Table 1), an oft-used metric in 
222 discussion of food web stability. Thus, Mill Creek Marsh, Oritani Marsh, and Harrier

223 Marsh are more qualitatively stable than Secaucus Marsh. Using Spearman rank

224 correlation, we document a strong relationship between qualitative stability and parasite

225 richness (Spearman's rho $=0.8)$.

226

227 DISCUSSION

228 Stable, predictable communities of organisms are thought to provide the

229 foundational resource for parasites with complex life cycles (Combes 2001; Poulin 2007).

230 The rationale being that in order to increase transmission, parasite life strategies become

231 integrally coupled with host species and rely on stable populations of hosts. Indeed, the

232 interaction between the parasite and its host is so vital that the death or absence of that

233 host will result in the death of the parasite. A logical extension of this premise is that

234 parasite species that rely on trophic interactions for transmission will only be present

235 when stable predator-prey trophic links exist in ecosystems (Marcogliese 2002; Anderson

236 \& Sukhdeo 2011). Our data appears to support this thesis, our lowest diversity site

237 (unrestored marsh) achieved the same parasite species richness as the more pristine,

238 highly diverse marsh sites (10 and 20 year marshes): these three sites had similar

239 stability, as measured by the fraction of eigenvalues that had negative real parts and

240 normalized connectance. The deviation in parasite species richness occurred in our 0

241 year marsh site. This site was only colonized directly transmitted parasites, and had a

242 significantly lower fraction of eigenvalues with negative real parts and a lower value of

243 connectance. The range of stability documented across our food webs suggests that there 
244 may be a critical threshold in the stability of host communities that is required for the 245 persistence of complex life cycle parasites.

246 Our sample sizes constrain our inferences, but our proposition is plausible given

247 that stable trophic interactions provide the critical connections allowing for trophic

248 transmission of parasites, and the apparent challenge of predicting parasite diversity at

249 large spatial scales. Indeed, Dobson et al. (2008) highlighted the difficulty in making

250 predictions about parasite diversity patterns across geographical boundaries because of

251 variation in the relationship between host diversity and parasite diversity. We suggest the

252 reason for this difficulty is that the community metrics correlating with parasite diversity

253 are not independent measures of system diversity, but also of the structure (cohesiveness)

254 and stability of the food web, an inherently local phenomenon.

255 The concept that our parasite community is structured by local interactions is

256 supported by the $\alpha$ - $\beta$ diversity dichotomy demonstrated in SACs. This dichotomy links

257 local and regional patterns of diversity (Gering \& Crist 2002) and allows for broad scale

258 inferences about the mechanisms driving species richness patterns. Specifically, whether

259 the community is the result of local or regional processes, and whether community

260 assembly is determined by niche or dispersal dynamics (Gotelli \& Colwell 2001; Dove \&

261 Cribb 2006). In $\alpha$-dominated communities, richness is concentrated in individual

262 samples, whereas $\beta$-dominated communities have dissimilar individual samples with

263 most species richness existing as regional turnover among samples. These patterns are

264 characterized by certain species accumulation curve (SAC) shapes: $\alpha$-dominated

265 communities have a steep slope that rapidly reaches asymptote, and $\beta$-dominated

266 communities have a more gradual slope and much later asymptotes. Our SAC data 
267 follows the shape exhibited by $\alpha$-dominated communities. This suggests interactive

268 processes that exist on a local scale determine the parasite community in killifish in our

269 system. Further, $\alpha$-dominated parasite communities are niche assembled, rather than

270 being limited by dispersal (Dove \& Cribb 2006). Thus, it strongly supports the notion

271 that the parasite species richness patterns in our focal species are the result of local

272 processes such as the structure and stability of trophic interactions.

273 The view that parasites are attached to stable community interactions is slowly

274 becoming a central theme in parasite ecology. This plays into a growing body of

275 evidence that has begun to address whether there are critical clusters of interactions

276 within free-living communities. Beginning with the work of Gilbert $(1977 ; 1979)$, and

277 continued by Thompson (2005; 2009), it has been argued that the identification of

278 interacting unit groups of species, in which natural selection acts upon all participants

279 significantly, will likely to provide considerable insight into community dynamics. These

280 unit groups, termed 'stable evolutionary units,' are the result of co-adaptation and

281 co-evolutionary processes based on their interactions (Thompson 1994; 2005). This

282 argument proposes that two populations of natural enemies (or mutualists) can co-adapt

283 and become dynamically stable over evolutionary time. Indeed, the existence of such

284 stable two-species interactions within communities may also facilitate a third species

285 (e.g., a parasite) that is able to adapt to, and exploit, the pre-existing interaction. For a

286 complex life-cycle parasite that relies upon trophic transmission, the initial predator/prey

287 interaction provides the critical unit in its establishment and persistence. In essence, the

288 structure of the host food web, exerts a strong selective pressure on the evolution of 
289

290

291

292

293

294

295

296

297

298

299

300

301

302

303

304

305

306

307

308

309

310

311

parasite transmission strategies and the subsequent patterns of parasite diversity observed in extant systems (Marcogliese \& Cone 1997; Poulin 2010; Anderson \& Sukhdeo 2011). A potential limitation of our study was our approach to analyzing the stability of the community without explicitly considering the effects of parasitism. There is a growing body of literature documenting that parasites affect host populations (Hudson, Dobson, \& Newborn 1998; Pedersen \& Greives 2008), and host communities (Wood et al. 2007). Parasites may even function as the thread that binds food webs together (Dobson et al. 2006): a likely consequence of complex life cycle parasites introducing relatively weak interactions into 'long loops' (Neutel et al. 2002). However, the effect of parasitism is not consistent across taxa: some parasitic species may have strong impacts on some species in their life cycle (e.g., Lafferty \& Morris 1996) but have weak or non-detectable impacts on others. This variation in effects is highlighted by theoretical work that struggled to adequately characterize empirical host-parasite topological networks (e.g., Petchey et al. 2008). The approach we take to qualifying stability, by randomly generating community matrices, overcomes the challenge of modelling variation in parasite effects and reflects the stability of the entire system. Our approach captures and includes the effects of pathogens - including bacteria, prions, viruses, and parasites - on host population dynamics, without explicitly considering them. We were primarily interested in the predictors of parasite richness and diversity, and we found that the local stability of free-living ecological communities is a good biological predictor.. Although our approach is simple, our conclusion that stable ecological systems support richer parasite fauna is also intuitive. Clearly, future studies must address the dynamic properties of ecological networks to provide a more realised understanding of how 
312 parasites respond to the host community, and how the free-living community responds to

313 parasitism.

314

315 CONCLUSIONS

316 Our data suggests that as a result of the dependence of parasites upon their

317 free-living hosts and the nature of the ecological network in which they reside, local

318 stability can strongly influence parasite establishment. Though parasites permeate entire

319 ecosystems - a position derived from the frequency of life cycles with one parasite

320 species interacting with many free-living hosts - it is apparent that they are not always

321 present, i.e., parasites do not appear to be everywhere all the time. Consequently, though

322 parasites substantially alter common food web metrics (Lafferty, Dobson, \& Kuris 2006),

323 we would caution against inference in studies where a parasite-host trophic link is

324 considered the equivalent of a predator/prey trophic link. Our approach posits that the

325 structural patterns of trophic interactions in host-based food webs can illuminate patterns

326 of parasite diversity and establishment (e.g., Anderson \& Sukhdeo 2011).

327

328 ACKNOWLEDGEMENTS

329 We acknowledge the assistance of Jesse Stratowski in the construction, installation, and

330 sampling of our experiment cages. 


\section{REFERENCES}

332

333

334

335

336

337

338

339

340

341

342

343

344

345

346

347

348

349

350

351

352

353

354

355

356

357

358

359

360

361

362

363

Allesina, S. \& Pascual, M. (2008) Network structure, predator-prey modules, and stability in large food webs. Theoretical Ecology, 1, 55-64.

Allesina, S. \& Tang, S. (2012) Stability criteria for complex ecosystems. Nature, 483, 205-208.

Anderson, R.C., Chabaud, A.G. \& Willmott, S. (1974) CIH Keys to the Nematode Parasites of Vertebrates. Commonwealth Agricultural Bureaux, England.

Anderson, T.K. (2009) Food Web Networks and Parasite Diversity. Ph.D. Thesis, Rutgers University.

Anderson, T.K. \& Sukhdeo, M.V.K. (2010) Abiotic versus biotic hierarchies in the assembly of parasite populations. Parasitology, 137, 743-754.

Anderson, T.K. \& Sukhdeo, M.V.K. (2011) Host centrality in food web networks determines parasite diversity. PLoS ONE, 6, e26798.

Anderson, T.K. \& Sukhdeo, M.V.K. (in press) The relationship between community species richness and the richness of the parasite community in Fundulus heteroclitus. The Journal of Parasitology, doi: 10.1645/GE-2940.1.

Bishop, Y.M. (ed). (2005) The Veterinary Formulary, 6th ed. The University Press, Cambridge.

Chen, H.-W., Liu, W.-C., Davis, A.J., Jordan, F., Hwang, M.-J. \& Shao, K.-T. (2008) Network position of hosts in food webs and their parasite diversity. Oikos, 117, 1847-1855.

Collinge, S.K. \& Ray, C. (eds). (2006) Disease Ecology: Community Structure and Pathogen Dynamics. Oxford University Press, Oxford.

Colwell, R. (2006) EstimateS: Statistical estimation of species richness and shared species from samples.

Combes, C. (2001) Parasitism: the Ecology and Evolution of Intimate Interactionsý. University Of Chicago Press, Chicago.

Criscione, C., Cooper, B. \& Blouin, M. (2006) Parasite Genotypes Identify Source Populations of Migratory Fish More Accurately than Fish Genotypes. Ecology, 87, 823-828.

de Meeûs, T. \& Renaud, F. (2002) Parasites within the new phylogeny of eukaryotes. Trends in Parasitology, 18, 247-251.

Dobson, A.P. \& Hudson, P.J. (1986) Parasites, disease and the structure of ecological 
communities. Trends In Ecology \& Evolution, 1, 11-15.

365

366

367

368

369

370

371

372

373

374

375

376

377

378

379

380

381

382

383

384

385

386

387

388

389

390

391

392

393

394

395

396

397

Dobson, A., Lafferty, K.D., Kuris, A.M., Hechinger, R.F. \& Jetz, W. (2008) Homage to Linnaeus: How many parasites? How many hosts? Proceedings of the National Academy of Sciences of the United States of America, 105, 11482-11489.

Dove, A.D.M. \& Cribb, T.H. (2006) Species accumulation curves and their applications in parasite ecology. Trends in Parasitology, 22, 568-574.

Gering, J.C. \& Crist, T.O. (2002) The á-â-regional relationship: providing new insights into local-regional patterns of species richness and scale dependence of diversity components. Ecology Letters, 5, 433-444.

Gilbert, A.J. (2009) Connectance indicates the robustness of food webs when subjected to species loss. Ecological Indicators, 9, 72-80.

Gilbert, L.E. (1977) The role of insect-plant coevolution in the organization of ecosystems. Comportement des Insectes et Milieu Trophique (ed V. Labyrie pp. 399-413. CNRS, Paris.

Gilbert, L.E. (1979) Development of theory in the analysis of insect-plant interactions. Analysis of Ecological Systems (eds D.J. Horn, R.D. Mitchell \& G.R. Stairs) p. 117. Ohio State University, Columbus.

Gotelli, N. \& Colwell, R. (2001) Quantifying biodiversity: procedures and pitfalls in the measurement and comparison of species richness. Ecology Letters, 4, 379-391.

Grenfell, B.T. \& Dobson, A.P. (1995) Ecology of Infectious Diseases in Natural Populations. Cambridge University Press, Cambridge.

Harris, C. \& Vogelbein, W. (2006) Parasites of mummichogs, Fundulus heteroclitus, from the York River, Virginia, USA, with a checklist of parasites of Atlantic coast Fundulus spp. Comparative Parasitology, 73, 72-110.

Hatcher, M.J., Dick, J.T.A. \& Dunn, A.M. (2006) How parasites affect interactions between competitors and predators. Ecology Letters, 9, 1253-1271.

Hoffman, G.L. (1999) Parasites of North American Freshwater Fish, 2nd ed. Cornell University Press, Ithaca.

Hudson, P.J., Dobson, A.P. \& Lafferty, K.D. (2006) Is a healthy ecosystem one that is rich in parasites? Trends In Ecology \& Evolution, 21, 381-385.

Hudson, P.J., Dobson, A.P. \& Newborn, D. (1998) Prevention of Population Cycles by Parasite Removal. Science, 282, 2256-2258.

Huspeni, T. \& Lafferty, K. (2004) Using Larval Trematodes That Parasitize Snails to Evaluate a Saltmarsh Restoration Project. Ecological Applications, 14, 795-804. 
Ives, A.R. \& Carpenter, S.R. (2007) Stability and diversity of ecosystems. Science, 317, 58-62.

Kuris, A.M., Hechinger, R.F., Shaw, J.C., Whitney, K.L., Aguirre-Macedo, L., Boch, C.A., Dobson, A.P., Dunham, E.J., Fredensborg, B.L., Huspeni, T.C., Lorda, J., Mababa, L., Mancini, F.T., Mora, A.B., Pickering, M., Talhouk, N.L., Torchin, M.E. \& Lafferty, K.D. (2008) Ecosystem energetic implications of parasite and free-living biomass in three estuaries. Nature, 454, 515-518.

Lafferty, K.D., Allesina, S., Arim, M., Briggs, C.J., De Leo, G., Dobson, A.P., Dunne, J.A., Johnson, P.T.J., Kuris, A.M., Marcogliese, D.J., Martinez, N.D., Memmott, J., Marquet, P.A., McLaughlin, J.P., Mordecai, E.A., Pascual, M., Poulin, R. \& Thieltges, D.W. (2008) Parasites in food webs: the ultimate missing links. Ecology Letters, 11, 533-546.

Lafferty, K.D., Dobson, A.P. \& Kuris, A.M. (2006) Parasites dominate food web links. Proceedings of the National Academy of Sciences of the United States of America, 103, 11211-11216.

Lafferty, K.D. \& Morris, A.K. (1996) Altered behavior of parasitized killifish increases susceptibility to predation by bird final hosts. Ecology, 77, 1390-1397.

Marcogliese, D. \& Cone, D. (1997) Food webs: A plea for parasites. Trends In Ecology \& Evolution, 12, 320-325.

Marcogliese, D.J. (2002) Food webs and the transmission of parasites to marine fish. Parasitology, 124 Suppl, S83-99.

May, R. (1972) Will a large complex system be stable? Nature, 238, 413-414.

May, R. (1973a) Stability and Complexity in Model Ecosystems. Princeton University Press, Princeton.

May, R. (1973b) Qualitative stability in model ecosystems. Ecology, 54, 638-641.

Mougi, A. \& Kondoh, M. (2012) Diversity of interaction types and ecological community stability. Science, 337, 349-351.

Mouritsen, K. \& Jensen, K.T. (1994) The enigma of gigantism - effect of larval trematodes on growth, fecundity, egestion and locomotion in Hydrobia ulvae (Pennant) (Gastropoda, Prosobranchia). Journal Of Experimental Marine Biology And Ecology, 181, 53-66.

Neutel, A.M., Heesterbeek, J.A.P., \& De Ruiter, P.C. (2002) Stability in real food webs: weak links in long loops. Science, 296, 1120-1123.

Pedersen, A.B. \& Greives, T.J. (2008) The interaction of parasites and resources cause crashes in a wild mouse population. Journal of Animal Ecology, 77, 370-377. 
Petchey, O.L., Beckerman, A.P., Riede, J.O., \& Warren, P.H. (2008) Size, foraging, and food-web structure. Proceedings of the National Academy of Sciences of the United States of America, 105, 4191-4196.

Poulin, R. (2007) Evolutionary Ecology of Parasitesý, 2nd ed. Princeton University Press, Princeton.

Poulin, R. (2010) Network analysis shining light on parasite ecology and diversity. Trends in Parasitology, 26, 492-498.

Poulin, R. \& Thomas, F. (1999) Phenotypic variation induced by parasites: extent and evolutionary implications. Parasitology Today, 15, 28-32.

Price, P.W. (1980) Evolutionary Biology of Parasitesý. Princeton University Press, Princeton.

Schell, S.C. (1970) The Trematodes. Wm. C. Brown Company, Dubuque, Iowa.

Thomas, F., Guegan, J.-F. \& Renaud, F. (eds). (2005) Parasitism and Ecosystems. Oxford University Press, Oxford.

Thompson, J. (1994) The Coevolutionary Process. University of Chicago Press, Chicago.

Thompson, J.N. (2005) The Geographic Mosaic of Coevolution. University of Chicago Press, Chicago.

Thompson, J.N. (2009) The coevolving web of life. The American Naturalist, 173, 125-140.

Wood, C.L., Byers, J.E., Cottingham, K.L., Altman, I., Donahue, M.J. \& Blakeslee, A.M.H. (2007) Parasites alter community structure. Proceedings of the National Academy of Sciences of the United States of America, 104, 9335-9339. 


\section{Table $\mathbf{1}_{\text {(on next page) }}$}

Summary of food web stability metrics for each estuarine food web.

Statistics include species richness $(S)$, potential links $\left(S^{2}\right)$, observed links $\left(L_{o}\right)$, linkage density $(d)$, connectance $(C)$, normalized connectance $\left(C_{\text {norm }}\right)$, minimum fraction of eigenvalues with negative real part (minE), average fraction of eigenvalues with negative real part (meanE), and maximum fraction of eigenvalues with negative real part (maxE). 


\begin{tabular}{lcccc}
\hline & Oritani & Secaucus & Harrier & Mill Creek \\
& Marsh & Marsh $(0$ & Marsh (10 & Marsh (20 \\
& & & & \\
Parameters: & (untouched) & year) & year) & year) \\
\hline Number of species; $\boldsymbol{S}$ & 71 & 87 & 112 & 122 \\
Potential no. of links; $\boldsymbol{S}^{2}$ & 5041 & 7569 & 12544 & 14884 \\
Observed no. of links; $\boldsymbol{L}_{\boldsymbol{o}}$ & 629 & 627 & 1206 & 1846 \\
Linkage density; $\boldsymbol{d}$ & 8.86 & 7.21 & 10.77 & 15 \\
Connectance; $\boldsymbol{C}$ & 0.125 & 0.083 & 0.096 & 0.124 \\
Normalized & 0.113 & 0.072 & 0.088 & 0.117 \\
& & & & \\
connectance; $\boldsymbol{C}_{\text {norm }}$ & & & & \\
MeanE & 0.839 & 0.771 & 0.851 & 0.803 \\
MaxE & 0.911 & 0.852 & 0.943 & 0.930 \\
MinE & 0.750 & 0.664 & 0.736 & 0.650 \\
\hline
\end{tabular}




\section{Table $2_{\text {(on next page) }}$}

Parasite community richness correlations between 4 salt marsh food webs.

Pairwise Spearman nonparametric correlation coefficients on mean parasite species richness observed in the killifish, Fundulus heteroclitus, in each site. 


\begin{tabular}{lcccc}
\hline & Oritani & Secaucus & Harrier & Mill Creek Marsh \\
& Marsh & Marsh (0 & Marsh (10 & (20 year) \\
& (untouched) & year) & year) & \\
\hline Secaucus Marsh & 0.772 & & & \\
Harrier Marsh & $0.913^{*}$ & 0.851 & \\
Mill Creek Marsh & $0.935^{*}$ & 0.822 & $0.957^{*}$ & \\
\hline * represent significant correlation at $p<0.05$. &
\end{tabular}




\section{Figure 1}

Species accumulation curves documenting parasite establishment and richness.

Asymptotic randomized sample-based species accumulation curves for Oritani Marsh (Unrestored), Secaucus Marsh (0 year), Harrier Meadow Marsh (10 year) and Mill Creek Marsh (20 year). Curves represent the result of the bias-corrected Chao2 estimator of species richness based on Fundulus heteroclitus samples collected weekly from fish cages. For each curve, each point represents the mean of 100 estimates using randomized accumulation order.

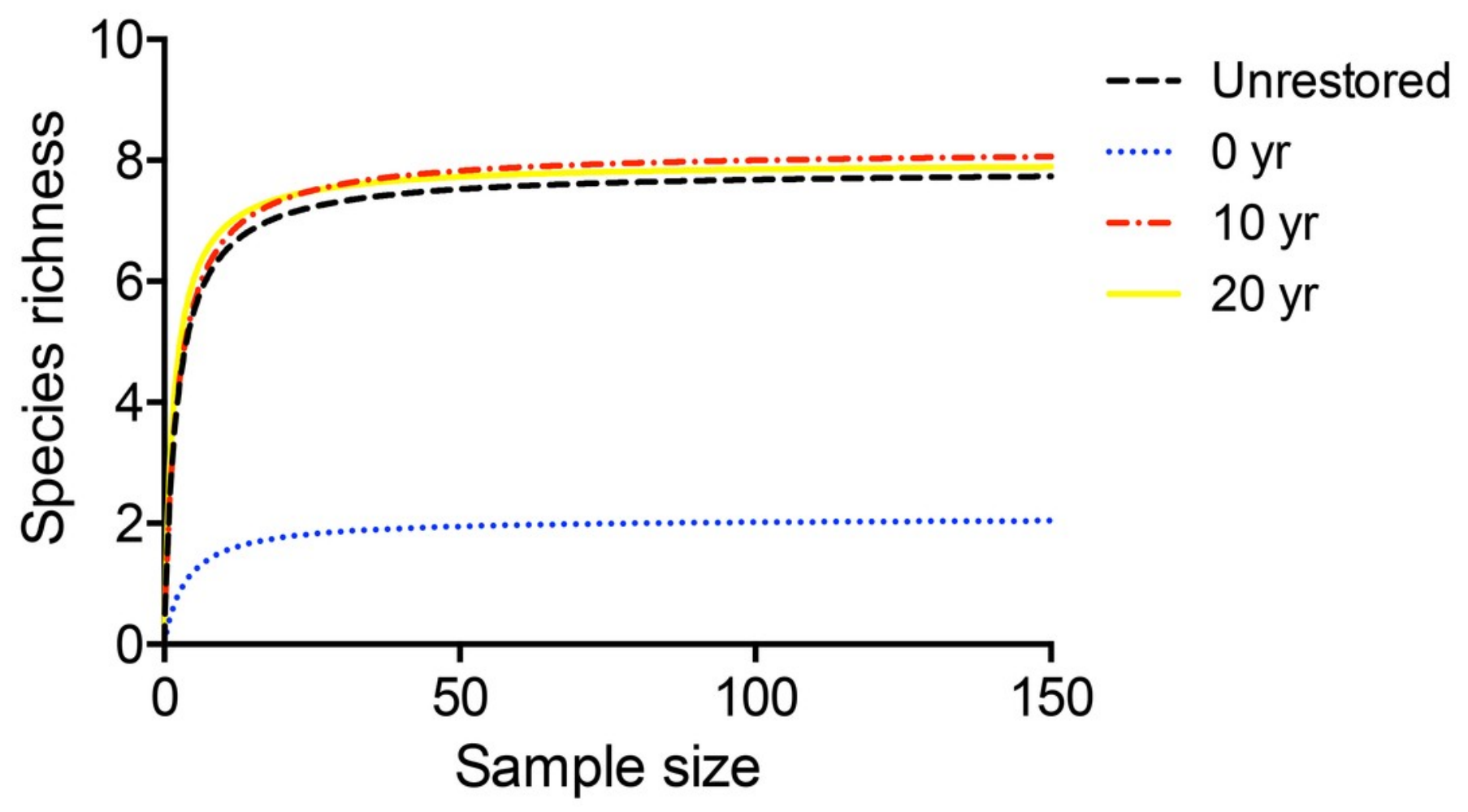




\section{Figure 2}

Qualitative stability in 4 estuarine marshes in New Jersey, USA.

Percentage of eigenvalues with a negative real part out of 100,000 simulations for: Oritani Marsh (Unrestored); Secaucus Marsh (0 year); Harrier Marsh (10 year); Mill Creek Marsh (20 year).

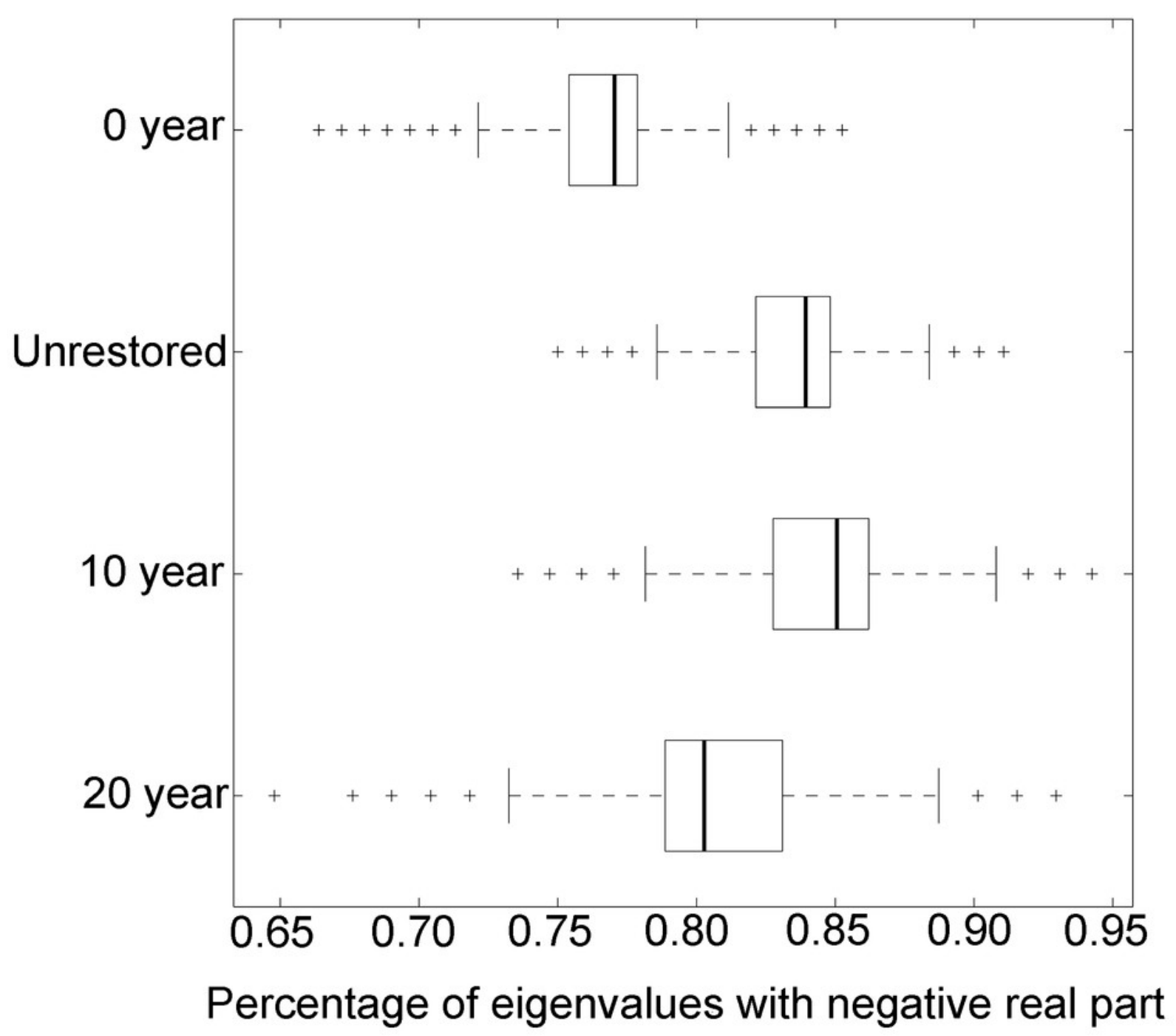

